\title{
INVISIBILIDADE E SILÊNCIO EM VIDAS PROVISÓRIAS, DE EDNEY SILVESTRE
}

\section{Laura Taddei Brandini ${ }^{1}$}

Resumo: Este artigo tem por objetivo analisar o romance Vidas provisórias (2013), de Edney Silvestre, tendo por foco a invisibilidade dos dois protagonistas, os brasileiros Paulo e Barbara, estrangeiros na Suécia e nos Estados Unidos, respectivamente. Tanto Paulo, exilado político nos anos de 1970, quanto Barbara, jovem imigrante em busca de melhores condições de vida na década de 1990, são invisibilizados pela perda de suas identidades e pelo silenciamento a que são submetidos em razão das dificuldades que apresentam para se comunicar nos idiomas estrangeiros. Busca-se, à luz de reflexões principalmente de Santiago (2004) e de Kristeva (1994), descrever e interpretar os modos de invisibilidade e silenciamento dos estrangeiros no referido romance.

Palavras-chave: Estrangeiro; Invisibilidade; Silêncio; Migração.

Abstract: This article aims to analyze the novel Vidas provisórias (2013), by Edney Silvestre, focusing on the invisibility of the two protagonists, Brazilians Paulo and Barbara, foreigners in Sweden and in the United States, respectively. Both Paulo, a political exiled in the 1970's, and Barbara, a young immigrant in search of better living conditions in the 1990's, are made invisible by the loss of their identities and the silence they are subjected to because of the difficulties they present to communicate in foreign languages. In the light of reflections mainly by Santiago (2004) and Kristeva (1994), we seek to describe and interpret the ways of invisibility and silence of foreigners in the referred novel.

Keywords: Foreigner; Invisibility; Silence; Migration.

1 Professora de Literatura Francesa, Teoria Literária e Teorias da Tradução no Departamento de Letras Estrangeiras Modernas da Universidade Estadual de Londrina 


\section{INTRODUÇÃO: A IMAGEM INVISÍVEL}

As Vidas provisórias (2013), do premiado romancista Edney Silvestre, bem poderiam ser transitórias, a se comprar o livro pela bela capa, composta por uma fotografia de Paolo Pellegrin, da agência Magnum, sobre a qual foi aplicado um filtro azul, em que vemos um homem a caminhar, sozinho, por um trilho de trem, em meio à neve, tendo um segundo trilho a compor uma linha paralela ${ }^{2}$. Esse homem, que não podemos identificar pois é quase uma silhueta, constitui-se como uma mancha escura na paisagem clara, algo que destoa do chão branco, marcado pelas linhas dos trilhos de trem. Evidentemente ele está em um espaço que não é o seu, transita por uma via que não é a sua.

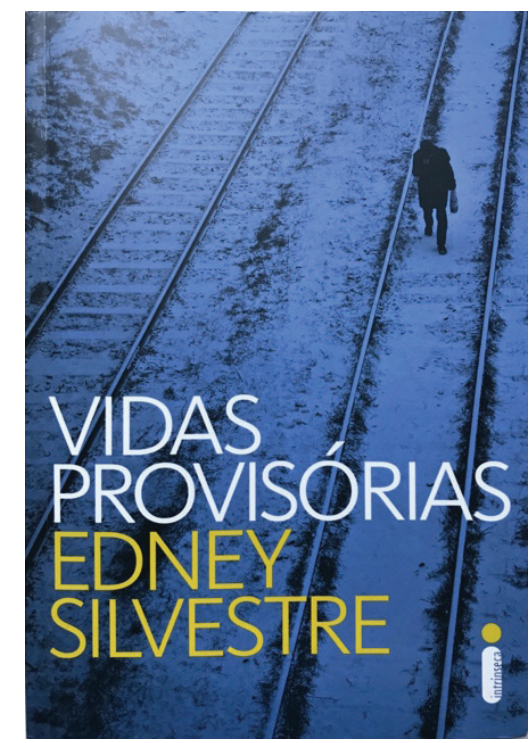

Fonte: Fotografia realizada pela autora: Capa do livro Vidas Provisórias, de Edney Silvestre.

Essa imagem representa as narrativas que compõem o romance: como se fossem dois caminhos paralelos, em capítulos alternados são contadas as histórias de Paulo e de Barbara. Ambos são imigrantes, brasileiros que se tornam estrangeiros recomeçando a vida em outros países, em viagens solitárias por trilhos desconhecidos. Não pertencem ao lugar onde estão, são como manchas escuras sobre um fundo claro. E, no entanto, caminham, avançam, para não sabem bem onde. Transitam pelo espaço estrangeiro vivendo vidas que, imaginam, são provisórias.

Paulo era estudante de pedagogia no Rio de Janeiro durante a ditadura militar, na década de $1970^{3}$. Acaba preso, torturado e deixado pelos militares na fronteira com o Paraguai. De lá vai para o Chile e depois, passando pela Argentina, embarca para a Suécia, onde obtém asilo e se apaixona por Anna, funcionária da Anistia Internacional, com quem se casa e constitui família. Perseguido pelas lembranças do passado que ainda o machucam e

2 Importante referir que o projeto gráfico do livro, incluindo a capa, é da empresa de design WARRAKLOUREIRO.

3 Cf. "Desenterrando os mortos: a abordagem do passado político brasileiro na obra de Edney Silvestre", de Gabriela Antunes, para uma análise do tema da ditadura na obra do escritor. 
ligam ao Brasil, sem falar sueco e com um inglês sofrível, Paulo se expressa com dificuldades e se equilibra entre sua identidade, que não existe mais oficialmente, uma vez que todos os seus documentos foram destruídos, as identidades que adotou durante a luta contra a ditadura e sua identidade de brasileiro exilado, estrangeiro.

A história de Barbara se passa em um outro momento histórico, os nem tão distantes anos 1990 de hiperinflação e de confisco do dinheiro das cadernetas de poupança, quando muitos brasileiros partiram para outros países em busca de melhores condições de vida. Barbara também partiu, com passaporte falso, rumo aos Estados Unidos, ao encontro do namorado brasileiro. Afastada do grupo com quem contava - o namorado e o irmão dele, já instalados no país -, a jovem sobrevive fazendo faxinas, agenciada por uma brasileira que também é cafetina. Sem amigos, isolada, não entende inglês, sua vida se resume ao trabalho e a alguns telefonemas lacônicos para a mãe, no Brasil, a quem manda dinheiro.

O projeto gráfico que marca cada uma das narrativas por uma cor de fonte e de papel diferentes - fonte preta sobre papel amarelado para Paulo, fonte azul sobre papel esbranquiçado para Barbara - delimita as duas histórias, que são lidas em paralelo e seguem um caminho comum, o dos estrangeiros assombrados pelo passado, seu companheiro mais familiar. Paulo e Barbara, cada um em sua narrativa, são, portanto, manchas escuras sobre um fundo claro, ou imagens invisíveis: como em uma fotografia ruim, eles podem ser vistos, mas não identificados.

\section{LUGARES PROVISÓRIOS}

De onde é o estrangeiro? Julia Kristeva, em Estrangeiros para nós mesmos, obra em que, de forma bastante ampla, revisita a noção de estrangeiro ao longo dos séculos, avisa: "Ele é estrangeiro, é de parte alguma, de todo lugar, cidadão do mundo, cosmopolita. Não o remeta às suas origens" (KRISTEVA, 1994, p. 36). O estrangeiro, portanto, tem raízes aéreas, móveis - compreendemos este termo como "passado" - ou simplesmente foram desenraizados, na ótica de Kristeva, o que se aplica a Paulo e a Barbara. Eles não podem se fixar em lugar nenhum: instalados predominantemente na Suécia e nos Estados Unidos, seus passados os empurram para outros lugares, outras vidas, tornando suas existências transitórias: Paulo passa do Rio de Janeiro ao Paraguai, a Santiago, a Buenos Aires, a Estocolmo, a Alvesta, a Härnösand, a Fisksätra, cidades suecas, a Paris, a Hatra, no Iraque, de onde escreve a carta que constitui seu último capítulo na narrativa. Barbara sai de São Paulo para Atlanta, vai para Framingham, no estado de Massachusetts, até chegar ao bairro do Queens, em Nova Iorque.

Todavia, seriam esses estrangeiros realmente "cosmopolitas", como aponta Kristeva? A etimologia grega da palavra remete à expressão "cidadão do mundo", no sentido tanto de alguém que vive em vários lugares diferentes, quanto é capaz de se adaptar aos modos de vida desses lugares. Ora, as "vidas provisórias" de Paulo e Bárbara evidenciam um outro lado do cosmopolitismo: eles devem viver muito longe de seus lugares de origem por força de imposições e um dos temas do romance é justamente sua dificuldade de adaptação às condições de vida oferecidas pelos países onde buscaram refúgio. Tais considerações ecoam 
de forma inequívoca o ensaio de Silviano Santiago, "Cosmopolitismo do pobre", em que trata da face perversa desse tipo de cosmopolitismo, não mais o do viajante rico que pode flanar despreocupadamente pelas ruas da cidade estrangeira, mas o do imigrante que anda apressado para não chegar atrasado em seu subemprego. Após refletir sobre o conceito tradicional de multiculturalismo, calcado na concepção dos Estados-nação e na ideia da assimilação do diferente, Santiago propõe:

Uma nova e segunda forma de multiculturalismo pretende (1) dar conta do influxo de migrantes pobres, na maioria ex-camponeses, nas megalópoles pós-modernas, constituindo seus legítimos e clandestinos moradores, e (2) resgatar, de permeio, grupos étnicos e sociais, economicamente desfavorecidos no processo assinalado de multiculturalismo a serviço do estado-nação. (2004, p. 59)

Para o autor, a forma atual do multiculturalismo deve compreender os fluxos migratórios propulsionados pela pobreza e tudo o que pode cercá-la, como o ato violento do assassinato do pai de Barbara que, aliado à periclitante situação econômica da família, provoca a decisão da personagem de partir para os Estados Unidos. Contudo, Santiago não prevê o exílio político, a expulsão do país por parte de autoridades com licença para torturar e matar, razão da partida - mesmo que involuntária - de Paulo. Trata-se, portanto, de mais uma categoria abrigada sob a aba da "segunda forma de multiculturalismo", aquela que se estabelece bem longe do glamour que o termo "cosmopolitismo" ainda guarda.

Como consequência desse "cosmopolitismo do pobre", Santiago aponta para uma forma de desigualdade social que ultrapassa fronteiras:

Está criada uma nova e até então desconhecida forma de desigualdade social, que não pode ser compreendida no âmbito legal de um único estado-nação, nem pelas relações oficiais entre governos nacionais, já que a razão econômica que convoca os novos pobres para a metrópole pós-moderna é transnacional e, na maioria dos casos, também é clandestina. O fluxo dos seus novos habitantes é determinado em grande parte pela necessidade de recrutar os desprivilegiados do mundo que estejam dispostos a fazer os chamados serviços do lar e de limpeza e aceitem transgredir as leis nacionais estabelecidas pelos serviços de migração. (2004, p. 51)

O caminho trilhado por Barbara se encaixa perfeitamente na descrição acima: menor de idade, ainda sem formação, sem perspectivas no Brasil, viaja sob uma falsa identidade argentina e vive de faxinas e serviços de manicure. O caminho de Paulo, embora tenha uma origem distinta, de ordem política, também conduz à condição de estrangeiro que, para sobreviver, acaba fazendo serviços mal remunerados e destinados àqueles que não têm qualificação profissional: trabalha como porteiro da noite e faxineiro em um pequeno hotel. Esses imigrantes, nos países desenvolvidos, constituem-se como uma face que, embora estranha - estrangeira -, não suscita o olhar do Outro, do cidadão sueco ou estadunidense. Como se estivessem lá apenas provisoriamente, estão e não estão naqueles lugares, são 
vistos, mas não enxergados. Kristeva define essa condição ambígua em uma frase: "Entre o homem e o cidadão, uma cicatriz: o estrangeiro" (1994, p. 102). Isto é, o estrangeiro se estabelece em um espaço entre duas categorias bem definidas e constitui-se como uma anomalia, uma mancha ou marca que não deveria existir, que enfeia o rosto hipocritamente sorridente da sociedade.

\section{INVISIBILIDADE}

Paulo e Barbara, como cicatrizes sociais, são muito pouco notados pelos cidadãos suecos e estadunidenses. Apenas duas pessoas parecem enxergá-los: Paulo é observado pela sueca Anna em uma reunião da Anistia Internacional. Ela se interessa por ele, por sua história, passa a amá-lo. Já Barbara transita unicamente pelos espaços dos demais brasileiros imigrantes, os únicos para quem ela parece existir desde que cumpra suas tarefas de faxineira, exceto para Silvio, que também a vê, e por quem a jovem se apaixona. Também, nas últimas linhas do romance, o sueco Edward, filho de pai brasileiro - justamente Paulo -, parece notar a jovem e fica no ar a promessa de uma nova história. As exceções confirmam a regra a que Paulo e Barbara são obrigados a se sujeitar: a da invisibilidade, da quase inexistência fora dos grupos de imigrantes.

Em artigo dedicado ao tema das migrações e dos refugiados, Leonardo Tonus aponta para a pouca frequência com que o tema aparece na literatura brasileira contemporânea, o que revela uma invisibilidade também no mercado editorial. Com base em dados sobre a tragédia das imigrações que assola o mundo atual e sobre como a arte tem lidado com ela, Tonus desenvolve uma interessante análise:

Contrariamente aos excluídos cuja "extração territorial" pressupõe uma visibilidade pela exposição dos procedimentos de estigmatização, o clandestino encarna uma forma radical de invisibilidade. Toda a sua existência organiza-se em função de um anonimato que, imposto e praticado cotidianamente, visa a não-revelação de sua diversidade em praça pública. [...] Ao apagar os rastros deixados pelos espaços pelos quais transita, o clandestino, que encarnam atualmente as figuras dos refugiados e dos migrantes, prenuncia a do estrangeiro [...]. (2018, p. [1])

Os protagonistas de Vidas provisórias são clandestinos que procuram não aparecer, escondem-se sob nomes e documentos falsos, em endereços periféricos que não fornecem a ninguém. Não estabelecem relações com os vizinhos, não criam raízes, estão sempre prontos para partir. Barbara, quando chega aos Estados Unidos, instala-se em meio à comunidade brasileira de Framingham, uma das maiores do país, onde vive seu namorado, Luís Claudio. Contudo, o perigo que a moça representa para o grupo por ter documentos falsos e por ser filha de um pai acusado de sequestro e morto pela polícia faz com que Leonardo a afaste da cidade, enviando-a para Nova Iorque, onde ela não será descoberta, como lhe é explicado: “- Muita gente vive e trabalha nos Estados Unidos sem documentos. Nova York é uma cidade grande, você vai sumir no meio de tanta gente que tem lá” (2013, p. 48), o que de fato 
ocorre. Já Paulo fracassa em seu esconderijo, uma vez que é encontrado em Fisksätra por seu irmão e algoz Antonio, militar que participou de suas sessões de tortura. Depois da visita inesperada e ameaçadora, Paulo se muda, com a família, para Paris, em nova tentativa de se tornar invisível aos olhos do irmão, protegendo sua mulher e seus filhos.

Não serem vistos, "sumirem", quase não existirem nos países estrangeiros faz com que os imigrantes Paulo e Barbara fiquem alheios ao mundo em que se encontram. Kristeva descreve essa maneira de existir própria aos estrangeiros na passagem abaixo:

A indiferença é a carapaça do estrangeiro: insensível, distante, no fundo ele parece fora do alcance das agressões que, contudo, sente com a vulnerabilidade de uma medusa. É que o afastamento onde o mantemos corresponde àquele em que ele próprio se aloja, recuando até o centro indolor daquilo que chamamos de alma, essa humildade que, definitivamente, constitui-se de uma nítida brutalidade. (1994, p. 15)

Estar alheio, não participar do mundo em que se vive por se pertencer ainda ao mundo em que se viveu, para os dois personagens, é sua condição de vida. Ser invisível, para Paulo, é indiferente: sua convivência social se restringe a Anna e a seus dois companheiros de exílio político, Ernesto e Chico Nelson, que, como ele, foram do Chile à Suécia e trabalham no mesmo hotel. Barbara, diferentemente, procura a invisibilidade como modo de se proteger, pois está no país ilegalmente. O ponto de vista do romance não é o mesmo explicitado por Kristeva quando esta enuncia "o afastamento onde o mantemos": em Vidas Provisórias lemos o afastamento onde Paulo e Barbara se mantêm, isto é, os dois protagonistas têm papel ativo na manutenção de suas situações localizadas à margem.

A indiferença de Paulo e a recusa de Barbara em se integrar aos países onde vivem constitui-se como uma estratégia de proteção: invisíveis, eles escapam aos olhares críticos das normas de comportamento social e até mesmo da lei. Nesse quadro, sobressai, em Vidas provisórias, o silêncio como forma de invisibilidade.

\section{A MÚSICA DO SILÊNCIO}

A música perpassa todo o romance. Em sua forma popular, de diversas nacionalidades, canções são cantaroladas baixinho e cantadas a plenos pulmões pelos personagens em vários momentos das duas narrativas. Logo no início, Paulo diz a Anna seu nome, "Nelson", ainda desconfiado, empregando o nome falso com que chegou à Suécia. Ela o associa ao almirante Nelson, comandante britânico da esquadra do Reino Unido na batalha de Trafalgar (1805), ao que Paulo responde, em seu inglês sofrível: “Almirante Nelson, não. Nelson cantor, understand? Cantor. Muito famoso no meu país. Foi o primeiro cantor cujo nome eu aprendi. Music. Music do meu país. Music of Brazil"' (SILVESTRE, 2013, p. 10). A própria identidade criada por Paulo durante a ditadura tem origem na música e seu codinome foi uma homenagem a Nelson Gonçalves.

O papel da música no romance é romper com o silêncio e dialogar com os persona- 
gens; ela se alterna entre dizer o que eles gostariam de dizer e dizer-lhes o que gostariam de ouvir. Na mesma cena do primeiro encontro com Anna, o desentendimento linguístico com Paulo é resolvido através da música "A Camisola do dia", de Herivelto Martins e David Nasser, imortalizada pela voz de Nelson Gonçalves, capaz de expressar o que o personagem não consegue dizer em inglês, ou seja, um elogio à sensualidade da mulher amada:

[...] Queria que ela percebesse que aquele momento mitigava inúmeras dores, mas não sabia como dizê-lo. Sem compreender por quê, como nunca fizera diante de alguém, muito suavemente, pouco a pouco, em voz baixa, mais como um sussurro, se ouviu entoando: A camisola do dia, / tão transparente e macia, / que eu dei de presente a ti, / tinha rendas de Sevilha, / a pequena maravilha,/ que o teu corpinho abrigava...

[...] $(2013$, p. 10-11).

$\mathrm{Na}$ narrativa de Barbara, as prostitutas brasileiras que lhe dão de presente de Natal uma camisola cantam a mesma canção de Nelson Gonçalves, evocando os momentos de baile em suas cidades natais. A música, então, funciona como se fosse uma porta para o passado, o passado brasileiro de Wanda, Lenira, Susana e Glória, anterior à vida de prostituição em Manhattan. Não fala pelas prostitutas, mas possibilita-lhes falarem de si a Barbara, contar-lhe suas histórias.

Ainda nesta narrativa, o segundo encontro de Barbara com Silvio, no apartamento de quem fora fazer faxina, é regido pela música que ele canta e dança euforicamente depois de ter recebido resultados positivos dos exames de controle da doença que o levará à morte. A letra de "I will survive", de Freddie Peerren e Dino Fekaris, expressa claramente o que ele gostaria de dizer - e diz, reproduzindo a voz de Gloria Gaynor:

Ele a pegou pelos ombros, deu-lhe um beijo em cada lado do rosto, pegou as bolsas que carregava, puxou-a para dentro.

- Sing with me, baby!

Barbara sorriu, sem graça.

- C’mon, queridona! Cante junto comigo e Gloria Gaynor:

Oh no, not I! I will survive! / Oh, as long as I know how to love /I know I'll stay alive! (2013, p. 156)

Se a música fala pelos personagens, ela também fala aos personagens. Em seu primeiro Natal sozinha em Nova Iorque, Barbara ouve a festa alegre de seus vizinhos peruanos para a qual não foi convidada. A música lhe diz o que ninguém mais dirá: 
Os vizinhos cantam, acompanhando a música alta. Ela reconhece a voz de Jose Feliciano. Feliz Navidad/ Feliz Navidad/ Feliz Navidad/ Prospero año/ Y felicidad... Não sabe o que fazer. Não queria estar aqui. Não: queria estar aqui, sim, mas não nesta situação. Mas não quer pensar nisso. (2013, p. 79)

A solidão de Barbara contrasta com a companhia e o amor de Anna por Paulo. Por ocasião do primeiro aniversário deste que comemoram juntos, Anna propõe um piquenique dentro do apartamento regado a vinho e a música. Eles trocam referências musicais: Paulo fala de Nelson Gonçalves, Nelson Cavaquinho, Pixinguinha, Noel Rosa, Maria Bethânia, Altemar Dutra, Geraldo Vandré e Milton Nascimento. Anna lhe fala de Jacques Brel, Johnny Hallyday, Sylvie Vartan, Françoise Hardy, Adamo, Christophe, Gilbert Bécaud. Por fim, entra em cena "Le Bel Âge", composição de 1964 da cantora e compositora francesa Barbara, a dizer a Paulo quem ele é:

A música abre com notas a piano. Então, suavemente, surge a voz da mulher. Barbara. Barbarrá, como lhe ensinou Anna há pouco. Il avait presque vingt ans/ Fallait, fallait voir/Sa gueule, c'était bouleversant/ Fallait voir pour croire. Sua voz não se parecia à de nenhuma cantora que ouvira antes. Era... rascante. Como seu nome. A l'abri du grand soleil/ Je ne l'avais pas vu venir/ Ce gosse, c'était une merveillel De le voir sourire (2013, p. 107-108)

Paulo não entende a letra da música, não fala francês. Anna traduz e pela letra da canção ela lhe fala, ele ouve, não se reconhece no jovem "de quase vinte anos", mas reconhece o amor daquela mulher por ele, que o envolve com o mesmo olhar terno do eu-lírico da canção de Barbara.

Vemos como a música se constitui como uma forma de expressão em Vidas provisórias, oferecendo aos personagens as palavras que eles não têm. Ela substitui o silêncio ao qual eles estariam submetidos, assegurando a comunicação, e acaba por se tornar um contraponto a este. A respeito do papel dos silêncios na música, convocamos as reflexões de John Cage, autor da obra Silêncio, coletânea de textos do autor. Em "Conferência sobre nada" (1959), escrita com os espaços que marcam o ritmo de leitura, o artista estabelece uma relação entre as palavras e os silêncios:

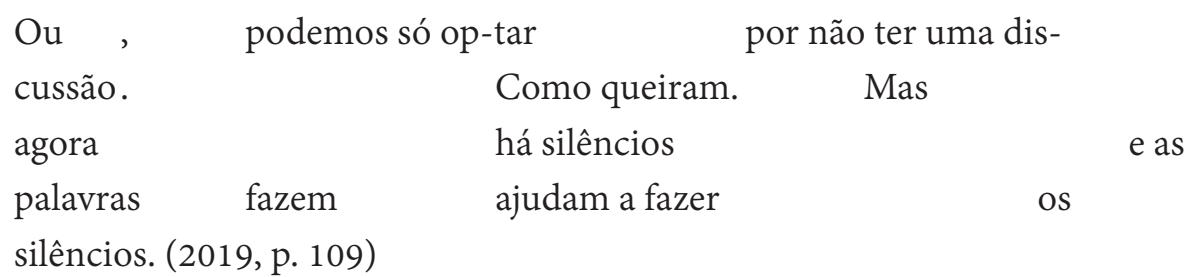

Palavras e silêncios se procuram e se repelem: são dependentes ao mesmo tempo em que não podem ocupar o mesmo espaço, pois são opostos. Palavras que "fazem, ajudam a fazer os silêncios", nos termos de Cage, também podem ser notadas em Vidas provisórias. Não do mesmo modo que vemos na conferência-partitura do artista norte-americano, que 
não só enuncia, como também pratica graficamente essa relação, porém em uma alternância entre falas e silêncios, em que um se constrói apoiando-se sobre o outro, sobre um fundo de questionamentos identitários.

\section{A LÍNGUA DO SILÊNCIO}

Tanto Paulo quanto Barbara deixam no Brasil suas identidades quando partem para os países estrangeiros. Paulo teve a sua apagada pelos torturadores. Em uma conversa com Anna, ele se exprime a respeito:

Eu não existo mais. Meus documentos foram destruídos. Minha certidão de nascimento, meus registros escolares, minhas fichas de emprego, tudo. Queimaram, rasgaram, picaram, sumiram com tudo o que havia em nome de Paulo Roberto Antunes. Eu fui extinto. (2013, p. 87-88)

Os registros de toda uma vida balizam a memória e ajudam a reconstruir o passado e a identidade dos personagens. Paulo se sente desenraizado desde que foi expulso do Brasil; sente que não existe mais. Quando Paulo acorda em um hospital, em Härnösand, depois de uma tentativa de suicídio, desnorteado e assustado, o narrador pergunta:

Que nome dissera ser o seu? Que nome usara? Qual deles? Nelson, Francisco, Alberto, Raul, Vítor, Carlos, Augusto, qual deles?

Errante. Novamente em fuga. Errantes. Ele e os brasileiros que já estavam exilados no Chile desde o golpe militar que derrubara João Goulart, em 1964. De novo em vidas provisórias. (2013, p. 51-52)

As vidas provisórias dos exilados políticos incluem novos nomes e a expropriação de seus passados. Arrancados violentamente de suas vidas, os personagens se equilibram entre o que não mais lhes pertence e a necessidade de reinvenção de uma identidade, mesmo que transitória, para atender às demandas burocráticas. Nesse quadro, nomes são apenas nomes, e tantos que Paulo nem sabe mais qual estava usando. Um nome para cada lugar, para cada situação diferente, para tentar despistar o passado de tortura de que ninguém que por ela tenha passado consegue se libertar. O passado "que era meu [de Paulo]" (2013, p. 74) deixa de ser sua infância, adolescência e juventude para dar lugar às marcas da violência física e psicológica deixadas pela ditadura.

Barbara, por sua vez, também trocou de identidade: escondeu-se sob um outro nome, uma outra história, para entrar e viver nos Estados Unidos:

Assim, carregando sua mala de marca falsa comprada na rua 25 de Março, Barbara - agora com sobrenome de origem italiana, mais aceitável do que o brasileiro Costa, agora filha de Abelardo e Laura Jannuzzi, e não mais de Carlos Roberto e 
Kátia da Costa, agora nascida em Buenos Aires, em 1970, e não mais em São Paulo, no dia 25 de janeiro de 1974, agora não mais assistente de serviços gerais do Smart English Course da rua Maria Paula, no Centro de São Paulo, mas estudante de biologia chegada para um intercâmbio ali mesmo no estado da Geórgia - vê as portas automáticas do aeroporto de Atlanta se abrirem [...]. (2013, p. 13)

O detalhe da mala - "falsa" - impregna toda a identidade de Barbara, que preserva somente seu prenome, a indicar, pela etimologia grega, "estrangeiro". Pelas frases negativas lemos quem era Barbara até passar pela imigração estadunidense, e o que ela deixa para trás assim que cruza a porta de saída:

Carimbam o visto de entrada, chamam o brasileiro seguinte na fila, ela contorna a cabine, caminha na direção que indica Exit, a primeira palavra que abafa o medo de ser pega antes mesmo de entrar no país para o qual foge, escorraçada por tudo o que a faz sentir-se irrelevante e esmagada no Brasil. (2013, p. 13)

A palavra "Exit" sinaliza não apenas uma saída, mas a entrada em uma nova vida, em uma nova identidade. Ao deixar sua vida no Brasil e entrar em uma vida de imigrante ilegal nos Estados Unidos, Barbara compreende que precisa ser invisível para sobreviver. Tanto ela, quanto Paulo, além de se invisibilizarem como um modo de se proteger do passado e das leis, são silenciados por sua condição de estrangeiros que não dominam os idiomas dos países onde vivem. A narrativa de Paulo se inicia por um trecho emblemático a esse respeito:

“What's your name?”, ela perguntou, enquanto o despia [...], na quarta língua em que tentava se comunicar. Ele não entendia sueco, como a maioria dos sul-americanos na reunião da Anistia Internacional em que o tinha conhecido, há algumas horas. Francês e alemão, os outros idiomas em que ela se movimentava com facilidade, tampouco tinham funcionado. (2013, p. 9)

Nos idiomas desconhecidos o personagem não consegue nem mesmo compreender a questão essencial que Anna lhe coloca, sobre sua identidade. Na língua inglesa eles conseguem se comunicar, porém muito precariamente. Paulo é silenciado por suas dificuldades com as línguas estrangeiras conhecidas por Anna a ponto de seu primeiro encontro ter acontecido praticamente sem palavras, como o personagem se esforça para se lembrar: “[...] Ela me tomou pela mão e me tirou da reunião. Não sei o que me disse. Não me lembro o que me disse, nem em que língua, nem mesmo se me disse alguma coisa para me tirar dali." (2013, p. 75).

A linguagem é um modo de apreensão do mundo para Paulo. Conversando com Anna, ele lhe conta que seu amigo de infância Eduardo lhe presenteava com palavras que, até então, eram-lhe desconhecidas. Na mistura do português com espanhol e inglês, Paulo tenta se expressar:

Ele me dava palavras. Words? É. Palavras. As palavras que eu não sabia o que 
significavam. Ele ia ao dicionário, anotava o significado em tiras de papel e me dava. Palabras. Like in Spanish. Não, Anna. Palavras com v, como em Viktor. Pa-la-vrras. Sim. Palavras. Quase todo dia ele me dava uma palavra. Ou mais. Várias, às vezes. [...] Tantas palavras. Que me ajudam a definir, até hoje me ajudam a definir, definir não, a dar uma forma, consistência ao que há em volta de mim, o que entendo, o que não entendo, tudo. Palavras, Anna. Na minha língua. Pa-la-vrrass. (2013, p. 86)

As palavras permitem a Paulo interagir com o mundo. Privado delas na Suécia, enquanto não domina o idioma, ele só encontra espaço em sua língua, como pontua a Anna. Em outro momento, no hospital, recém-chegado à Suécia, requer o uso de seu idioma para se ouvir e afastar os fantasmas dos torturadores do passado:

- Estou com febre, estou com frio - diz, em voz alta, precisando se ouvir para que o som da própria voz traga alguma consistência ao que o rodeia. - Isto é um delírio. Tenho febre. Febres provocam delírios. Ninguém está falando comigo. Eu é que estou falando comigo. E estou delirando.

Os velhos se viraram para ouvi-lo.

- Estou falando português. Eu preciso falar português. Ouvir minha voz. Não a voz dele. Não a voz do doutor Sérgio. Não. Não. Não, não, não... (2013, p. 53)

Sua voz só sai se for em português, em gritos desesperados para se desvencilhar das lembranças da tortura. Seu idioma é convocado para se sobrepor à voz do torturador, como se fosse um porto seguro, ou seu único meio de romper o silêncio da incomunicabilidade linguística. Novamente, vemos a linguagem como instrumento de interação, mas dessa vez esta se dá consigo mesmo, em substituição à interação com a lembrança de um de seus algozes. Depois da visita ameaçadora de seu irmão Antonio, que o encontrou, e à sua família, em Fisksätra, Paulo experimenta a necessidade de contar a Anna tudo sobre o seu passado. E ele o faz em português, o idioma em que consegue se expressar com plenitude, forçando a mulher a tentar acompanhá-lo:

- You don't have to ask for forgiveness. Não precisa dizer nada - ela fala, no melhor português que consegue.

Preciso, Anna. Preciso falar. Preciso falar agora. Porque eu não disse a verdade quando me perguntou se eu tinha irmãos e irmãs. Eu menti. Disse que não tinha. E que meu pai tinha morrido. Eu menti, Anna. Menti porque tinha vergonha.

- Why were you ashamed? Why? Ashamed for what?

Vergonha de ter um irmão torturador. Assassino, talvez. [...] 


\section{$[\ldots]$}

Paulo utiliza palavras em inglês, em sueco, uma ou outra em português, sem perceber a mistura que faz. Usa tudo o que sabe, pode e se lembra para se comunicar com Anna. Agora, mais que nunca, não pode haver barreira separando-o da mulher que lhe deu um filho. (2013, p. 166)

O temor causado pela aproximação de Antonio faz com que Paulo lute para restabelecer a verdade com as armas que tem: palavras. Não se trata de frases ou expressões, mas apenas de palavras, tudo o que consegue articular dentro de suas limitações de conhecimento de línguas estrangeiras. Contudo, parece que palavras lhe bastam, como quando as ganhava de seu amigo Eduardo. No exílio, portanto, é por meio de "palavras em inglês, em sueco, uma ou outra em português" (2013, p. 166) que o personagem rompe o silêncio a que é submetido por sua condição de estrangeiro, para olhar novamente para o seu passado doloroso e compartilhá-lo com Anna.

As palavras também faltam a Barbara, em qualquer idioma. Logo ao chegar aos Estados Unidos, recepcionada no aeroporto de Atlanta por Luís Claudio e o irmão Leonardo, a moça não compreende o que este lhe diz: "[Leonardo] Diz alguma coisa em voz baixa e rouca. Ela não entende. Após uma breve hesitação, percebendo que a fitam aguardando uma reação, responde o que lhe parece adequado." (2013, p. 13).

A conversa de surdos, em que uma pessoa endereça a palavra a outra e esta não entende, procurando responder o que "The parece adequado", também se dá em inglês, idioma que Barbara não fala, nem compreende. Ao fazer planos para quando terminar de pagar sua dívida para com Luís Claudio e Leonardo, que lhe conseguiram o passaporte argentino e o dinheiro da passagem, lemos: "Mas, antes, precisava aprimorar o inglês. Não tinha ideia de que sabia tão pouco inglês e de que falava tão mal, até chegar aqui. Deduz, mais do que entende o que lhe dizem." (2013, p. 42). Em outro momento, volta a seus antigos sonhos e novamente a língua estrangeira aparece como um problema:

Você era a jovem que ia estudar medicina, ou biologia, ou inglês para se tornar secretária bilíngue, as vozes insistem em lembrar, e hoje limpa apartamentos, faz unhas e depilação em Nova York. Quando você decidiu ir embora de São Paulo, deixar a mãe, os parentes, ou os poucos amigos, era esse o futuro almejado? A vida em um país cuja língua até hoje não consegue falar ou entender direito? Um apartamento de três cômodos (sala-quarto, cozinha, banheiro), mobiliado com móveis do Exército da Salvação? (2013, p. 116)

Em contraponto aos sonhos que acalentava quando ainda vivia no Brasil, a voz narrativa focaliza a dificuldade de Barbara com o idioma e a exiguidade de sua morada. Não estão presentes o medo de ser descoberta pelas autoridades, o trabalho árduo que precisa executar diariamente, a rudeza com que as patroas a tratam, o desapontamento com Luís Claudio, a solidão em que vive imersa, a preocupação com a saúde de Silvio, o pouco dinheiro que recebe e que, em grande parte, é destinado a pagar sua dívida. Tudo se resume a uma 
vida dentro da incompreensão linguística, confinada no pequeno apartamento quando não está trabalhando e, consequentemente, silenciada.

Esse silenciamento se configura como um modo de invisibilidade que contamina a aparência da personagem. Indignado com a vida solitária da jovem, Silvio fica sem palavras diante do apagamento do corpo de Barbara:

- Vinte e quatro anos, Barbara! Vinte e quatro! Você está no auge da juventude! Vinte e quatro anos, Barbara! O que está esperando para sair por aí aproveitando esse... esse... - aponta o corpo sem relevos, coberto por uma blusa descolorida e calças jeans, em busca de palavras. - Essa juventude toda? Solte esses cabelos! Passe um batom! Onde está a sua bolsinha de maquiagem?

- Não trouxe. Não uso. Você sabe. (2013, p. 97)

O corpo sem atrativos, escondido sob roupas anódinas e sem cor, o rosto sem maquiagem alguma: nada em Barbara chama a atenção e tudo obedece ao princípio da invisibilidade protetiva. Como Leonardo prenunciara, Barbara iria "sumir" em Nova Iorque, não seria descoberta e poderia seguir sua vida. Uma vida, contudo, de anulação das linguagens (corporal e verbal), logo, de silêncio.

Essa estratégia de sobrevivência é colocada à prova pelas pessoas para quem ela trabalha: "As Peruas mal se dirigem a ela. É invisível, como são as empregadas delas no Brasil. As Cachorras lhe fazem muitas perguntas. A maioria ela não sabe responder." (2013, p. 114). Sua camuflagem funciona junto às Peruas. Junto às Cachorras, Barbara pratica o silêncio, por não saber responder, nem querer saber as respostas. Sua carapaça de neutralidade, que a torna invisível, é, contudo, penetrada pelo passado que a lembra quem ela é:

O passado volta de muitas formas. [...] Mas [as vozes do passado] são o bastante para tirá-la da neutralidade em que conseguiu se proteger. As vozes lembram que ela não é apenas mais uma mulher, agora já não tão jovem, a atravessar uma avenida de Nova York, quando a luz verde do sinal comanda: walk. Ou a faxineira invisível a aspirar o pó acumulado durante uma semana sob a poltrona da Ikea. (2013, p. 115)

A invisibilidade em que vive é perturbada por suas dores: a perda do apoio de Luís Claudio, única pessoa que conhecia quando chegou ao país estrangeiro, a morte violenta de seu pai, a doença de Silvio que o matou aos poucos. Mas rapidamente Barbara afasta as vozes das lembranças e se fecha às dores que a individualizam com palavras em português. Ela cantarola uma canção infantil bastante conhecida: "Pela estrada afora,/ Eu vou bem sozinha/ Levar esses doces/ Para a vovozinha./ A estrada é longa,/ O caminho é deserto,/ E o lobo mau passeia aqui por perto./ Mas à tardinha,/ Ao sol poente,/ Junto à mamãezinha/ Dormirei contente." (2013, p. 116). Fica evidente a enunciação, pela música, do próprio caminhar de Barbara, sozinha, em um espaço estrangeiro, sem poder contar com a ajuda de ninguém, à mercê de perigos, mas com a esperança de um final feliz. Mais uma vez, um 
personagem de Vidas provisórias necessita das palavras de outros para poder se expressar, rompendo o silêncio a que é submetida.

\section{CONCLUSÃO}

A libertação da prisão do silenciamento para os dois protagonistas surge, mais uma vez, pela palavra, com a leitura de poesia. Paulo lê os versos de "The Road not taken", de Robert Frost, identificando-se com o eu-lírico que não pode percorrer os dois caminhos que se apresentam a ele o que, obrigatoriamente, enseja uma perda: "Leu-o e releu-o inúmeras vezes durante a noite. Quis apossar-se dele. Sentia que Robert Frost falava do que ele, Paulo, conhecia. Dos caminhos que outros não tomaram mas que ele, Paulo, sim.” (2013, p. 70). Os versos de Frost, portanto, falam não somente a Paulo, mas de Paulo.

Por sua vez, Barbara também encontra na poesia as suas próprias palavras. No eu-lírico de "One Art", de Elizabeth Bishop, ela se espanta em se reconhecer:

O que a atrai e espanta é descobrir que alguém, algum dia, alguém a quem nunca viu e que nunca a viu tampouco, alguém que viveu em outra época, em situação diversa da sua, seja capaz de expressar tão claramente o que, para ela, Barbara, sempre foi tão vago, tão difuso, tão incomensurável. Há duas semanas ela abre o livro no metrô, no ônibus, no banco da praça, enquanto come um sanduíche; há duas semanas ela abre o livro em casa, abre onde tiver chance e sempre cai, comovida, na página 40. Sempre na mesma frase. The art of losing isn't hard to master. (2013, p. 232)

A perda de uma vida possível, diferente das vidas de exilado e imigrante ilegal, é o tema que une os poemas que entusiasmam Paulo e Barbara, pois permitem que ambos se reconheçam nas vozes líricas de Frost e Bishop. Mesmo em língua estrangeira, esses poetas falam pelos personagens, conferem forma, imagem e voz a suas realidades, moldando-as com palavras, tal como Paulo fazia ao receber os presentes de Eduardo. São mensagens de libertação que rompem com a barreira da incompreensão dos idiomas e reativam suas identidades, pois falam de suas vidas, dores e perdas e apontam para a literatura - compreendida aqui também na música - como meio de Paulo e Barbara restabelecerem suas visibilidades por meio da fala. A poesia, em suma, ajuda os dois a recuperarem suas vozes e existências em busca de vidas menos provisórias e mais perenes. 


\section{REFERÊNCIAS BIBLIOGRÁFICAS}

ANTUNES, Gabriela. "Desenterrando os mortos: a abordagem do passado político brasileiro na obra de Edney Silvestre”. Brasiliana - Journal for Brazilian Studies. Londres, vol. 3, n 1, p. 139-160, julho de 2014. Disponível em: https://tidsskrift.dk/bras/article/view/16754. Acesso em 25/09/2020.

CAGE, John. "Conferência sobre nada”. In: Silêncio. Conferências e escritos de John Cage. Tradução de Beatriz Bastos e Ismar Tirelli Neto. Rio de Janeiro: Cobogó, 2019, p. 126-109.

KRISTEVA, Julia. Estrangeiros para nós mesmos. Tradução de Maria Carlota Carvalho Gomes. Rio de Janeiro: Rocco, 1994.

SANTIAGO, Silviano. O Cosmopolitismo do pobre: crítica literária e crítica cultural. Belo Horizonte: Editora UFMG, 2004.

SILVESTRE, Edney. Vidas provisórias. Rio de Janeiro: Editora Intrínseca, 2013.

TONUS, José Leonardo. “Migrantes e refugiados: à (a) espera de uma narrativa?” Letras de hoje. Porto Alegre, vol. 53, n 4, p. [1], outubro a dezembro de 2018. Disponível em: https://www.scielo.br/scielo. php?script=sci_arttext\&pid=S1984-77262018000400476. Acesso em 25/09/2020. 
